\title{
Education
}

\section{Performance on ABA- ASA In-training Examination predicts success for RCPSC certification}

Ramona A. Kearney MD FRCPC, Patrick Sullivan MD FRCPC, Ernest Skakun PhD

Purpose: Most Canadian University Departments of Anesthesia require residents to take the American Board of Anesthesiology-American Society of Anesthesiologists (ABA-ASA) in-training examination (ITE). The result is expressed as a percentile relative to all examinees at similar levels of training. Its value as a predictor of performance in the Royal College of Physicians and Surgeons of Canada (RCPSC) certification examinations is not known.

Methods: All English speaking Canadian residency programs in Anesthesia were surveyed. Results of the ABA-ASA ITE of former residents who had completed RCPSC certification were collected as percentile scores according to level of training. Level of training was based on the number of months of anesthesia training and classified according to American residency program nomenclature. The ABA-ASA ITE scores were correlated with success on the RCPSC written and oral examinations. The probability of success on the RCPSC examinations was determined by calculating the cutoff score with the best sensitivity and specificity as determined by Receiver Operating Characteristic (ROC) curves for each year in which the examination was taken and for both the written and oral examinations.

Results: Nine residency programs provided information on 165 residents. A weak positive correlation was found between scores on each year of the ABA-ASA exam. Scores $>50$ th percentile for any year were highly predictive of success in the written component ( $>60$ th percentile for the oral component). Scores $<20$ th percentile were predictive of failure on both the written and oral components of the RCPSC examination.

Conclusion: The ABA-ASA ITE is a useful tool in predicting performance on the RCPSC examination.

Objectif : La plupart des départements d'anesthésie des universités canadiennes exigent de leurs résidents qu'ils se présentent à l'examen américain des résidents en cours de formation de l'American Board of AnesthesiologyAmerican Society of Anesthesiologists (ABA-ASA) in-training examination (ITE). Le résultat est exprimé en percentile relatif au nombre total de candidats au même niveau de formation. Sa valeur prédictive de performance à l'examen de certification du Collège royal des médecins et chirurgiens du Canada (CRMCC) n'est pas connue.

Méthode : Tous les programmes canadiens anglais de résidence en anesthésie ont été étudiés. Les résultats de I'ABA-ASA ITE des anciens résidents qui se sont présentés à l'examen du CRMCC ont été recueillis et cotés selon le niveau de formation. Le niveau de formation a été fondé sur le nombre de mois de formation en anesthésie et classé selon la nomenclature du programme américain de résidence. La corrélation des scores d'ABA-ASA ITE avec les examens écrits et oraux du CRMCC a été un succès. La probabilité de réussite des examens du CRMCC a été déterminée par le calcul de la cote minimale ou maximale du meilleur taux de sensibilité et de spécificité établis au moyen de l'analyse par les courbes ROC pour chaque année où l'examen a été fait et pour les examens oraux et écrits.

Résultats : Neuf programmes de résidence ont fourni des renseignements sur 165 résidents. Une faible corrélation positive a été découverte entre les scores de chaque année d'examen de l'ABA-ASA. Les scores $>50$ e percentile, quelle que soit l'année, ont été fortement prédictifs de succès pour la composante écrite de l'examen et les scores $>60^{\circledR}$ percentile, pour la composante orale. Les scores $<20^{\circledR}$ percentile ont été prédictifs d'échecs aux examens oraux et écrits du CRMCC.

Conclusion : L'ABA-ASA ITE est utile pour prédire la performance à l'examen du CRMCC.

From the Departments of Anesthesiology and Pain Medicine, Division of Studies in Medical Education, University of Alberta and University of Ottawa, Canada.

Address correspondence to: Dr. R.A. Kearney, Department of Anesthesiology and Pain Medicine, University of Alberta, Room 3B2.32, 8440

- 112 Street, Edmonton, Alberta T6G 2B7 Canada. Phone: 780- 407-2689; Fax: 780-407-3200; E-mail: rkearney@gpu.srv.ualberta.ca Accepted for publication June 13, 2000. 
$\mathrm{P}$ ROGRAM directors and their residency program committees are responsible for implementing the general standards of accreditation set out by the RCPSC. In this role it is expected that residents will be evaluated against a standard of performance commensurate with their level of training. ${ }^{1}$ Knowledge is assessed using written and oral examinations devised within individual departments and standardized in-training examinations developed by American specialty boards or societies. The in-training examination is thought to be an excellent tool to assess knowledge. ${ }^{2}$ Several studies have shown the predictive value of an in-training examination on performance in the certifying examinations in Internal Medicine, ${ }^{3,4}$ Family Practice, ${ }^{5}$ Surgery ${ }^{6}$ and Psychiatry ${ }^{7}$ for the American specialties.

For many years, Canadian residency programs in Anesthesia have taken advantage of the American Board of Anesthesiology-American Society of Anesthesiologists (ABA-ASA) in-training examination (ITE). This is a multicentre multiple choice examination administered annually and residents obtain a percentile ranking according to level of training. This is a high quality examination which can assess the resident's knowledge base. Program directors try to infer from the examination results whether the resident will be successful on the Canadian certification examinations. The relevance of the percentile scores to the RCPSC examination is unknown, making predictions difficult. The purpose of this study is to investigate the usefulness of the ABA-ASA ITE in predicting success on the RCPSC certification examinations.

\section{Methods}

The program directors of all English speaking Canadian residency programs in Anesthesia were surveyed. The information requested of the program directors included the results of the ABA-ASA ITE of former residents who had completed the certification examinations of the RCPSC. Examination results were stated as percentile scores according to level of training. Also reported were the number of attempts at the written and oral certification examinations and whether success or failure occurred. Former residents were identified to the authors only by program, year of RCPSC examination and an assigned identification number.

Because the American residency programs are four years long and have a different nomenclature, Canadian residents were classified according to the American system based on the number of months of training in Anesthesia. The American designations are as follows: clinical base year $(\mathrm{CB})=0-1$ month of anesthesia training, first clinical anesthesia year (CA-1)
= 2-12 months of anesthesia training, second clinical anesthesia year $($ CA-2 $)=13-24$ months of anesthesia training, third clinical anesthesia year $(\mathrm{CA}-3)=25-36$ months of anesthesia training.

Percentile scores on the ABA-ASA ITE were grouped into five distinct score ranges and the pass rate on the RCPSC examinations for each range was calculated. To determine the relationship between the ABA-ASA ITE percentile scores and success on the RCPSC written and oral examinations, Pearson product - moment correlations were computed. This type of correlation was selected because success on the RCPSC written and oral examinations is a dichotomous variable.

Because we used a continuous score to predict a dichotomous outcome, the best cutoff score needed to be determined. Establishing optimal cutoff scores or cut points uses a technique dating from the early days of radar and sonar detection called the Receiver Operating Characteristic curve (ROC). This technique operates on the premise that as the sensitivity of the radio is increased, we pick up both the desired sound as well as static. Initially the signal increases faster than the static but at some point there is a crossover and the static grows faster than the signal. The optimal setting is where we detect the largest ratio of signal to static. ${ }^{8}$ In this study the "signal" is the number of residents passing the RCPSC examinations; the "static" is the number of residents who fail the RCPSC examinations but scored above the cutoff on the ABA-ASA ITE. Arbitrary cut points in the scores were chosen and $2 \times 2$ tables were used to calculate their sensitivity and specificity. These pairs of sensitivities and specificities were then graphed on an ROC where the cutoff point with the best discriminating ability is determined (most signal, least static). This is indicated by the cutoff point nearest the upper left corner on the graph. This was completed for each year in which the examination was taken and for both the written and oral examinations. Likelihood ratios were calculated to determine the post-test probabilities of success given the pretest probability of success of the cohort. The probability of success of a resident in the RCPSC exams according to the year in which the ABA-ASA ITE is taken was determined.

Results

Nine of 13 programs provided information on 165 former residents. The ABA-ASA ITE was written once by 59 residents, twice by 52 residents, three times by 43 residents and four times by 11 residents. The correlations between success on the first attempt at the RCPSC written examination and the scores on the 
TABLE I Pass rates of Canadian residents (with ABA-ASA classification) on the written component of the RCPSC examination (\%):

\begin{tabular}{lllllllll}
\hline $\begin{array}{l}\text { ABA-ASA } \\
\text { Percentile }\end{array}$ & \multicolumn{2}{c}{$C B$} & \multicolumn{2}{c}{$C A-1$} & & $C A-2$ & & \\
\hline$</=20$ & $3 / 9$ & $(33)$ & $7 / 12$ & $(58)$ & $7 / 9$ & $(78)$ & $4 / 6$ & $(67)$ \\
$21-40$ & $8 / 8$ & $(100)$ & $13 / 18$ & $(72)$ & $5 / 8$ & $(63)$ & $3 / 4$ & $(75)$ \\
$41-60$ & $4 / 5$ & $(80)$ & $30 / 32$ & $(94)$ & $24 / 28$ & $(86)$ & $5 / 6$ & $(83)$ \\
$61-80$ & $6 / 6$ & $(100)$ & $25 / 25$ & $(100)$ & $34 / 34$ & $(100)$ & $16 / 16$ & $(100)$ \\
$81-100$ & $12 / 13$ & $(92)$ & $34 / 34$ & $(100)$ & $33 / 33$ & $(100)$ & $18 / 18$ & $(100)$ \\
Overall & $33 / 41$ & $(80)$ & $109 / 121$ & $(90)$ & $103 / 112$ & $(92)$ & $46 / 50$ & $(92)$ \\
\hline
\end{tabular}

TABLE II Pass rates of Canadian residents (with ABA-ASA classification) on the oral component of the RCPSC examination (\%):

\begin{tabular}{|c|c|c|c|c|c|c|c|c|}
\hline \multirow{2}{*}{$\begin{array}{l}\text { ABA-ASA } \\
\text { Percentile } \\
</=20\end{array}$} & \multicolumn{2}{|c|}{$\mathrm{CB}$} & \multicolumn{2}{|c|}{ CA-1 } & \multicolumn{2}{|c|}{ CA-2 } & \multicolumn{2}{|c|}{ CA-3 } \\
\hline & $5 / 6$ & (83) & $3 / 8$ & (38) & $5 / 7$ & (71) & $2 / 5$ & $(40)$ \\
\hline $21-40$ & $4 / 8$ & (50) & $11 / 13$ & (85) & $3 / 6$ & (50) & $3 / 4$ & (75) \\
\hline $41-60$ & $2 / 3$ & (67) & $25 / 30$ & (83) & $18 / 24$ & (75) & $3 / 4$ & (75) \\
\hline $61-80$ & $4 / 6$ & (67) & $21 / 22$ & (95) & $26 / 28$ & (93) & $15 / 16$ & (94) \\
\hline $81-100$ & $11 / 11$ & $(100)$ & $27 / 29$ & (93) & $31 / 32$ & (97) & $18 / 18$ & (100) \\
\hline Overall & $26 / 34$ & (76) & $87 / 102$ & (85) & $83 / 97$ & (86) & $41 / 47$ & (87) \\
\hline
\end{tabular}

ABA-ASA ITE, according to year of training at the time of the examination, were poor to moderate $(r=$ $.346-.469)$. Between success on the first attempt at the RCPSC oral examination and the ABA-ASA ITE the correlations were similar $(\mathrm{r}=.281-.510)$. Correlations between the ABA-ASA ITE and subsequent attempts at the RCPSC examinations were not computed due to the small number of cases.

The success rates on the written component of the RCPSC examination for various percentile ranges on the ABA-ASA ITE show that scores higher than the 60th percentile are associated with a high likelihood of success in the RCPSC examinations, whereas scores less than the 20th percentile are associated with a high likelihood of failure. (Table I) For example, all Canadian residents designated CA-1 who obtained a score above the 60th percentile on the ABA-ASA ITE passed the RCPSC written component, whereas $42 \%$ of residents scoring below the 20th percentile failed the RCPSC examination.

The success rates on the oral component of the RCPSC examination follow a similar distribution with an increased likelihood of passing the RCPSC examination when scores on the ABA-ASA ITE above the 60th percentile are obtained. The likelihood of failure increases with lower ABA-ASA ITE scores although this trend is less clear than that of the written component. (Table II) For example, most Canadian residents designated CA-2 writing the ABA-ASA ITE who obtained a score above the 60th percentile passed the RCPSC oral component but the failure rate at lower scores was paradoxically greater with scores between the 21 st and 40th percentile than with those scoring below the 20th percentile.

The probability of success on the RCPSC written examination was calculated together with sensitivity and specificity at defined cutoff scores. (Table III) The cutoff scores chosen indicate the ABA-ASA ITE score at which the resident has approximately a $90 \%$ chance of passing the written component of the RCPSC examination. The likelihood of failing the RCPSC examination if this score is not achieved lies between 25-67\%. For example, if a resident writes the ABA-ASA ITE in his CB year and achieves a score at the 55th percentile, then he has a $94 \%$ chance of passing the RCPSC written examination. If this resident scores at the 15 th percentile then his chance of failure is $67 \%$.

The probability of success on the RCPSC oral examination was calculated together with sensitivity and specificity at defined cutoff scores. (Table IV) Cutoff scores were chosen again to approximate a $90 \%$ chance of success. The likelihood of failing the RCPSC examination if this score is not achieved is between 31$38 \%$. For example, if a resident writes the ABA-ASA ITE in his CB year and achieves a score at the 55th percentile, then he has an $89 \%$ chance of passing the RCPSC oral examination. If this resident scores at the 15 th percentile then his chance of failure is $38 \%$.

Discussion

The goals of evaluation of resident performance are both formative and summative. Residents benefit from 
TABLE III Sensitivity, Specificity and Predictive Values of ABA-ASA ITE scores for the written RCPSC examination (Canadian residents classified by the ABA-ASA ) :

\begin{tabular}{llllll}
\hline $\begin{array}{l}\text { Year of } \\
\text { Training }\end{array}$ & $\begin{array}{l}\text { ABA-ASA Exam } \\
\text { Cut-Off Score }\end{array}$ & Sensitivity & Specificity & $\begin{array}{l}\text { Probability } \\
\text { of Passing if } \\
\text { Score } \geq \text { Cutoff }\end{array}$ & $\begin{array}{l}\text { Probability } \\
\text { of Failure if } \\
\text { Score }<\text { Cutoff }\end{array}$ \\
\hline C B & $>20$ & .91 & .75 & 94 & 67 \\
CA1 & $>40$ & .81 & .83 & 98 & 33 \\
CA2 & $>50$ & .80 & .78 & 98 & 25 \\
CA3 & $>30$ & .89 & .75 & 98 & 38 \\
\hline
\end{tabular}

TABLE IV Sensitivity, Specificity and Predictive value of ABA-ASA ITE scores for the oral RCPSC examination (Canadian residents classified by the ABA-ASA ):

\begin{tabular}{llllll}
\hline $\begin{array}{l}\text { Year of } \\
\text { Training }\end{array}$ & $\begin{array}{l}\text { ABA-ASA Exam } \\
\text { Cut-Off Score }\end{array}$ & Sensitivity & Specificity & $\begin{array}{l}\text { Probability } \\
\text { of Passing if } \\
\text { Score } \geq \text { Cutoff }\end{array}$ & $\begin{array}{l}\text { Probability } \\
\text { of Failure if } \\
\text { Score }<\text { Cutoff }\end{array}$ \\
\hline CB & $>50$ & .62 & .75 & 89 & 38 \\
CA1 & $>50$ & .76 & .73 & 94 & 33 \\
CA2 & $>60$ & .70 & .79 & 95 & 31 \\
CA3 & $>60$ & .80 & .83 & 97 & 38 \\
\hline
\end{tabular}

formative evaluations which, through appropriate feedback, enable the resident to identify strengths and weaknesses and provide direction for future learning. Residency program committees benefit by identifying residents with difficulties in developing and organizing their knowledge base, enabling residents to focus their personal study programs and, if necessary, providing remediation. In Canadian Anesthesia residency programs, annual and/or semi-annual written and oral examinations devised within the individual departments are administered. This task is often onerous and the resulting examination may often be fraught with numerous technical item flaws which impair reliability and prevent valid assessments of the resident's progress from year to year.

Most Canadian Anesthesia programs have utilized the ABA-ASA ITE for reasons previously mentioned. Additional benefits include the ability to compare a resident's progress with that of his/her cohort and to compare a resident's progress from year to year. Unfortunately, only the global score is provided in percentile form. As a formative tool, a profile of performance on subscales of the exam, which is currently provided only as a raw score, would be more useful in percentile form. Regardless, consistently high scores in this examination tend to reassure both the program committee and the resident that success on the RCPSC examinations is likely, while variable and poor scores may have the opposite effect. Our data indicate that useful information can be obtained from this examination.
Correlation coefficients were poor to moderate. This may be due to the comparison of percentile ranks with dichotomous scores (pass-fail), to the small number of residents in the study or to a true difference between the subject matter on the American and Canadian examinations. We were unable to obtain the actual scores of the RCPSC examination as the data were collected retrospectively and the location of these former residents was often unknown making it impossible for scores to be released.

The numbers in the study are small and the correlations were affected by a number of residents who failed the RCPSC examination while obtaining ABAASA ITE scores greater than the 80th percentile. For example the $92 \%$ pass rate on the RCPSC written examination for those residents obtaining an ABAASA ITE score greater than the 80th percentile is the failure of one out of 13 residents. Success rates on either component of the RCPSC examination ranged from $76 \%-92 \%$ depending upon level of training at the time of the exam.

Whether there is a true difference between the funds of knowledge of residents in Canadian training programs vs American training programs is unknown. Residents in Canadian programs take an additional year of training in general internal medicine which may influence the content of the examination. When the American Board of Pediatrics in-training examination was administered to pediatrics residents in Italy a difference in scores was seen. It was felt that the 
emphasis of the examination was different from that of the Italian training program. ${ }^{8}$ They did note that the Italian residents scores were different from those typically seen in American and Canadian residents implying that there was no difference between residents scores of the latter two countries.

Observation of the pass rates on the RCPSC examination indicates a high likelihood of success when percentile scores on the ASA-ABA ITE were high. Determination of the post-test probabilities of success confirm this observation. The cutoff scores were chosen based on the assumption that their position at the upper left-hand corner of the ROC curve minimized error. This is so when the pretest probability of success is close to $50 \%$. Success rates on the RCPSC exam ranged from $76 \%-92 \%$ as mentioned above. When the post-test probabilities were recalculated taking into account the corrected pretest probability, the results did not differ.

\section{Conclusion}

The ASA-ABA ITE is a commonly used method for evaluating knowledge in residents in Canadian Anesthesia programs. We were unable to show good correlations between percentile scores on the ITE and Canadian certifying examinations. The likelihood of pass or failure on the RCPSC examination based on the results of the ABA-ASA ITE was calculated. Residents consistently scoring at higher than the 60th percentile have approximately a $90 \%$ chance of success on the RCPSC exams. This study confirms the ABAASA ITE as a predictor for success in the RCPSC examinations and its utility as a formative evaluation tool. Canadian program directors and residency training committees can identify residents requiring remediation based on the results of the ABA-ASA ITE.

\section{Acknowledgements}

The authors wish to thank the residency program directors for their cooperation in collecting the information from their respective programs.

\section{References}

1 General Standards of Accreditation, The Royal College Of Physicians And Surgeons of Canada, September 1997.

2 Holmboe ES, Hawkins RE. Methods for evaluating the clinical competence of residents in Internal Medicine: a review. Ann Intern Med 1998; 129: 42-8.

3 Waxman H, Braunstein G, Dantzker D, et al. Performance on the Internal Medicine second-year residency In-training Examination predicts the outcome of the ABIM certifying examination. J Gen Intern Med 1994; 9: 692-4.
4 Grossman RS, Fincher R-ME, Layne RD, Seelig CB, Berkowitz LR, Levine MA. Validity of the In-Training Examination for predicting American Board of Internal Medicine certifying examination scores. J Gen Intern Med 1992; 7: 63-7.

5 Leigh TM, Johnson TP, Pisacano NJ. Predictive validity of the American Board of Family Practice In- Training Examination. Acad Med 1990; 65: 454-7.

6 Shetler PL. Observations on the American Board of Surgery In-Training Examination, board results, and conference attendance. Am J Surg 1982; 144: 292-4.

7 Webb LC, Junl D, Reynolds CF III, et al. How well does the Psychiatry residency In-Training Examination predict performance on the American Board of Psychiatry and Neurology Part I examination? Am J Psychiatr 1996; 153: 831-2.

8 Streiner DL, Norman GR. Health Measurement Scales, 2nd ed. New York: Oxford University Press Inc., 1995.

9 Butzin DW, Guerin RO, Oliver TK, Stockman JA, Da Dalt L, Perilongo G Administering the American Board Of Pediatrics In-Training Examination in a European Pediatrics residency (Letter). Acad Med 1996; 71: 393-4. 